\title{
Peripheral T cell receptor beta immune repertoire is promptly reconstituted after acute myocardial infarction
}

\author{
Dan $\mathrm{Li}^{1}$, Longgang Hu${ }^{3}$, Qing Liang ${ }^{2}$, Cuijuan Zhang ${ }^{1}$, Yunzhen Shi ${ }^{4}$, Bin Wang ${ }^{2}$ and Kejia Wang ${ }^{2 *}$
}

\begin{abstract}
Background: Acute myocardial infarction (AMI) is characterized by an inflammatory process in which T cell plays a key role. However, the profile of immune microenvironment in AMl is still uncertain. High-throughput sequencing of T cell receptor (TCR) provides deep insight into monitoring the immune microenvironment.

Methods: 30 patients with AMI were enrolled and 30 healthy individuals were recruited as controls. Flow cytometer were used to analyze the distribution of a $\beta$ T cells and their CD69 expression from peripheral leukomonocytes. TCR $\beta$ repertoire library was amplified by two-round multiplex PCR and detected by next-generation sequencing (NGS).

Results: The percentage of a $\beta$ T cells in AMI patients were significantly restricted than those in healthy controls, while the highly activated a $\mathrm{\beta}$ T cells along with distinguishing usage of variable $(V)$, diversity $(D)$ and joining $(J)$ gene segments were also found in AMl patients. In addition, AMl induced a significantly restricted CDR3 amino acid (AA) diversity and remarkably reconstituted TCR immune repertoires. Finally, we identified several AMI-associated tendency of CDR3 AAs expression after AMI.
\end{abstract}

Conclusions: Our work suggests that the aberrant a $\beta$ T cells distribution and activation may associated with the pathogenesis of AMI and demonstrates a reconstitution of TCR $\beta$ immune repertoire after AMI.

Keywords: T cell receptor beta, Immune repertoire, Acute myocardial infarction, Next-generation sequencing

\section{Background}

Acute myocardial infarction (AMI), considered a lipidrelated chronic inflammatory disease, often occurs on the basis of coronary atherosclerosis [1]. In general, AMI induces considerable remodelling of the myocardial tissue which leads to abnormal contractile function and heart failure, both constituting the prevailing cause for morbidity and mortality worldwide [2]. There is a global increase in the incidence of AMI in both male and female. It is estimated that AMI is responsible for over 8 million deaths each year, accounting for $5 \%$ of the global burden of disease [3].

\footnotetext{
*Correspondence: princewkj@qdu.edu.cn

${ }^{2}$ College of Basic Medicine, Qingdao University, Qingdao, Shandong, China

Full list of author information is available at the end of the article
}

Currently, it is widely accepted that $\mathrm{T}$ cells are the main immune competent cells meditated development of atherosclerotic plaques and local thrombosis [4]. It is believed that AMI is associated with $\mathrm{T}$ cell-associated cytokine imbalance that may act as predictors for ischemic heart disease outcomes [5, 6]. The myocardium is subject to myocardial ischaemia-reperfusion injury induced by re-establishment of blood flow though the majority of AMI patients is received prompt reperfusion. Emerging studies indicate that critical role of $\mathrm{T}$ cell in the pathogenesis of AMI injury and post myocardial infarction healing [7]. The balance of $\mathrm{T}$ cell-meditated immunity by the host is a major determinant of patient outcome [8], and overactive T cells, continually, lead to the progression of inflammatory response, resulting in organ dysfunction. Therefore, the potential immunosuppressive approaches may be used for the treatment of patients affected by AMI $[8,9]$. Interestingly, the 
decrease of $\mathrm{T}$ lymphocyte count occurs in the circulatory system after AMI $[10,11]$. The intrinsic mechanism between $\mathrm{T}$ cell response and AMI injury is still to need further exploration.

$\mathrm{T}$ cells can be divided into two major subsets characterized by the surface expression of a TCR $\alpha$ and $\beta$ chain ( $\alpha \beta \mathrm{T}$ cell) or $\gamma$ and $\delta$ chain ( $\gamma \delta \mathrm{T}$ cell). A majority of $\mathrm{T}$ cells in peripheral blood expresses is $\alpha \beta \mathrm{T}$ cells, while only $5-10 \%$ lymphocytes in peripheral blood are $\gamma \delta \mathrm{T}$ cells. $\mathrm{T}$ cells bear unique TCRs generated by random somatic recombination of $\mathrm{V} /(\mathrm{D}) / \mathrm{J}$ gene segments. $\mathrm{T}$ cell priming requires TCR ligation, by the cognate major histocompatibility complex (MHC) on antigen-presenting cells (APCs) to recognize antigens $[12,13]$. It is considered that $\alpha \beta \mathrm{T}$ cells can sense external environmental trigger (viral or bacterium infection) and an endogenous stimulus (homeostasis) by TCR to mediate immunosurveillance and immunoregulation, and TCR will be reconstituted in response to stimuli (infection and disease) [14-16]. Nevertheless, the association of TCR repertoires in AMI has not been clarified as yet.

In the basis of recent literature and finding, we hypothesized that $\alpha \beta \mathrm{T}$ cells exert a critical function in the pathogenesis and pathophysiology of AMI, and an essential evolution of TCR repertoires may be found due to AMI-induced aberrant inflammatory microenvironment. In this study, we detected the count and activity of $\alpha \beta \mathrm{T}$ in peripheral blood, and NGS was used to monitor the expression pattern and clonality of TCR repertoire of $\alpha \beta$ $\mathrm{T}$ cells in AMI patients. The manipulation of the heartspecific TCR immune repertoires can improve our basic understanding of $\mathrm{T}$ cell immunology and help to identify optimal TCRs for immunotherapy.

\section{Methods}

\section{Participants}

A total of 30 patients who diagnosed with AMI admitted to the Department of Cardiology, The Affiliated Hospital of Qingdao University were enrolled. The criteria for diagnosis of AMI patients were based on the third Universal Definition of Myocardial infarction: (1) Acute ischemic chest pain within $24 \mathrm{~h}$; (2) Electrocardiogram change of acute myocardial infarction (pathological Q wave, ST-segment elevation or depression) and (3) Rise of cardiac biomarkers cTnI level [17]. The diagnosis was confirmed by coronary angiogram at the admission and all of AMI patients were received reperfusion by primary percutaneous intervention (PCI) concomitantly. Additionally, 30 healthy individuals without clinical sign of myocardial ischaemia were included as controls. This study was approved by the Ethics Committee of The Affiliated Hospital of Qingdao University and written informed consent was obtained from each participant.

\section{Lymphocytes isolation and flow cytometry analysis}

Peripheral blood samples of patients with AMI was obtained within $24 \mathrm{~h}$ of the onset of symptoms, the blood of patients with controls were obtained immediately after hospital admission. The blood cell count was performed using Sysmex XN (Sysmex Corporation, Kobe, Japan) in the clinical laboratory of our hospital. Lymphocytes were isolated by using Ficoll (Solarbio Life Sciences, Beijing, China) density gradient centrifugation according to instruction. Subsequently, the isolated cells were washed twice with PBS for further experiments. To detect the $\alpha \beta \mathrm{T}$ cells, isolated lymphocytes were incubated with fluorescently conjugated antibodies directed against mouse CD3e (HIT3a), TCR $\alpha / \beta$ (IP26) and CD69 (FN50) from Biolegend (Beijing, China) for $20 \mathrm{~min}$ at room temperature in the dark. Cell counting was conducted using a $\mathrm{BD}$ Accuri C6 (BD Biosciences, Mountain View, CA, USA) and data was obtained and analyzed with BD Accuri C6 Software (BD).

\section{RNA extraction and TCR repertoires library preparation} RNAprep Pure Cell/Bacteria Kit (Tiangen Biotech, Beijing, China) was used to extract RNA from the isolated lymphocytes. The quality and quantity of RNA were measured by using a NanoDrop spectrophotometer (Thermo Fisher Scientific, USA). First-strand cDNA was synthesized using a Transcriptor First Strand cDNA Synthesis Kit (Roche Applied Science, Penzberg, Germany) according to the manufacturer's protocol on a T100TM Thermal Cycler (Bio-Rad Inc., CA, USA). A total of 200 ng RNA was performed in the reverse transcription reaction. TCR $\beta$ repertoire library was prepared by tworound multiplex PCR using specific primers designed for functional $\mathrm{V}$ and $\mathrm{C}$ gene segments of TCR $\beta$ chain (Additional file 1: Fig. S1). TCR $\beta$ chain repertoire amplification was performed as described in our previous work [18]. The PCR products were loaded on 1\% TBE-Agarose for gel electrophoresis and purified using the QIAquick Gel Extraction Kit (Qiagen). Illumina HiSeq X Ten platform was used for high-throughput sequencing of TCR $\beta$ chain repertoire.

\section{Data processing}

Paired-end V, D and J sequences of TCR $\beta$ chain were identified using BLAST Plus on IMGT database (http:// www.imgt.org/) by a standard algorithm after filtering the low-quality reads. Heatmaps and circular plots were created to reflect the frequencies of $\mathrm{V}$, J gene segments and paired V-J combinations, respectively. Gini coefficient, Shannon diversity and Rank-abundance were used 
for assessing the richness and diversity of TCR as previously described [19-21].

\section{Statistical analysis}

All statistical analyses were performed using GraphPad Prism 6.0 (GraphPad Software, La Jolla, CA) using a 2-tailed, unpaired Student's t-test or Mann-Whitney U test was for two groups comparisons. Data are presented

Table 1 Baseline characteristics of the enrolled subjects

\begin{tabular}{|c|c|c|c|}
\hline & $\begin{array}{l}\text { Healthy } \\
\text { controls } \\
(n=30)\end{array}$ & AMI patients $(n=30)$ & $P$ value \\
\hline Age (year) & $57.6 \pm 11.6$ & $58.8 \pm 10.4$ & NA \\
\hline Gender (male/female) & $17 / 13$ & $18 / 12$ & NA \\
\hline $\begin{array}{l}\text { Arterial hypertension } \\
(\%)\end{array}$ & $30 \%$ & $40 \%$ & NA \\
\hline Diabetes mellitus (\%) & $20 \%$ & $30 \%$ & NA \\
\hline Smoking (\%) & $23.3 \%$ & $30 \%$ & NA \\
\hline History of AMI (\%) & 0 & 0 & NA \\
\hline BMI $\left(\mathrm{kg} / \mathrm{m}^{2}\right)$ & $25.8 \pm 2.2$ & $26.4 \pm 3.3$ & NA \\
\hline $\begin{array}{l}\text { Total cholesterol } \\
(\mathrm{mmol} / \mathrm{L})\end{array}$ & $5.04 \pm 1.28$ & $5.12 \pm 1.24$ & NA \\
\hline $\mathrm{cTnl}(\mathrm{ng} / \mathrm{mL})$ & $56.8 \pm 56.5$ & $0.012 \pm 0.040$ & $<0.001$ \\
\hline
\end{tabular}

$B M I$ body mass index, CTnI cardiac troponin-I as the mean \pm standard deviation. Significance was accepted at $P<0.05$.

\section{Results}

Clinical characteristics of the subjects

Demographic characteristics and baseline clinical features of participants including gender, age, past medical history and biochemical data were summarized in Table 1. No significant differences were observed with gender, age, hypertension, diabetes mellitus, total cholesterol and history of smoking between two groups. The concentration of cTnI was significantly higher in AMI patients than that in healthy controls (Table 1). We also found that levels of peripheral WBC and neutrophils were significantly elevated in AMI patients (Fig. 1a, b). Interestingly, the percentage of lymphocytes was significantly decreased in AMI patients compared to controls (Fig. 1c), and the concentration of cTnI was negatively associated with lymphocytes levels (Fig. 1d). No significant variation in monocytes levels was verified in AMI patients (Fig. 1e).

\section{AMI activates $\alpha \beta T$ cells in AMI patients}

To explore the status of $\alpha \beta$ T cells in response to AMI, we measured the population of $\alpha \beta$ T cells from peripheral blood by using flow cytometer. As expected, a lower

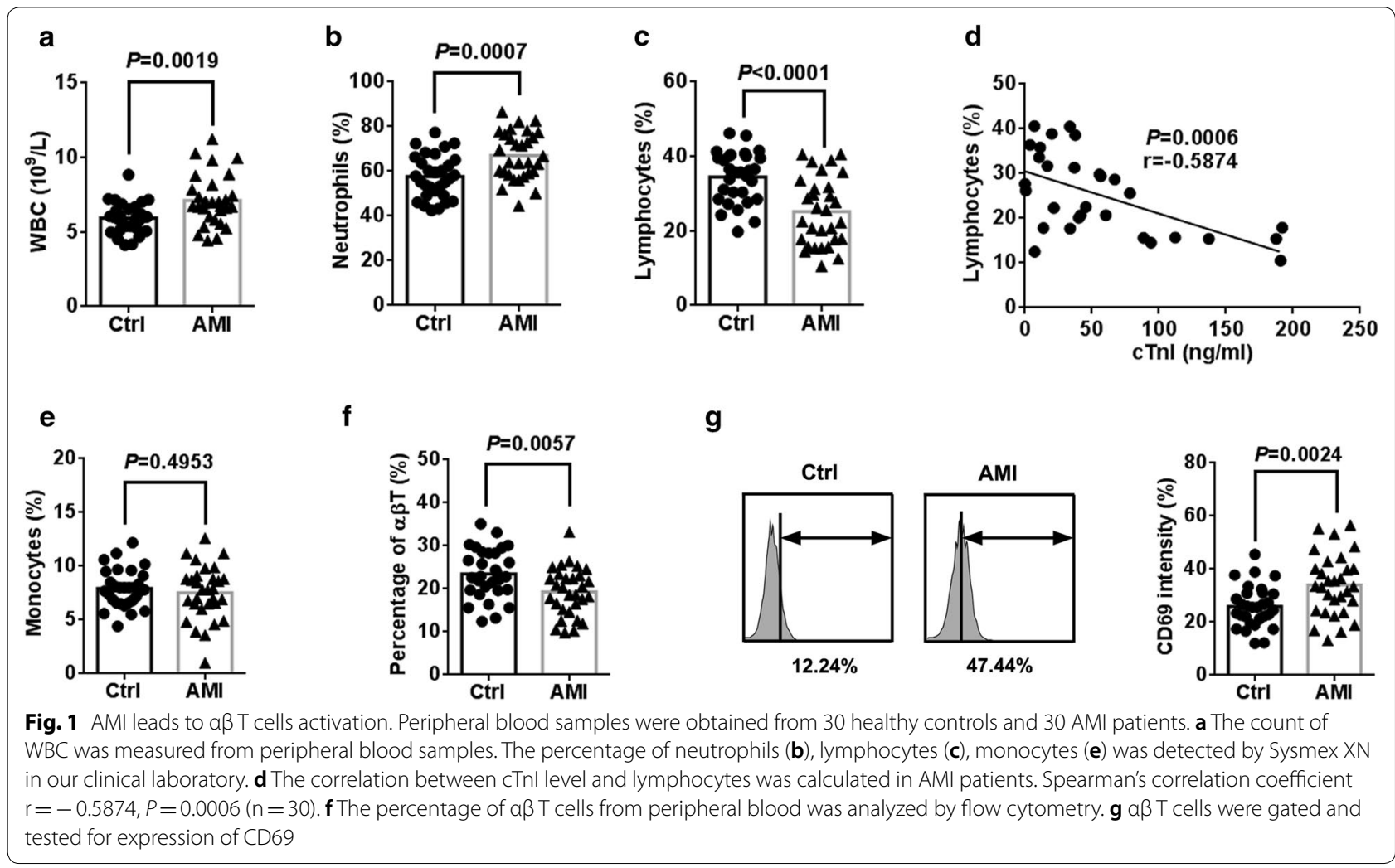


percentage of peripheral $\alpha \beta$ T cells were observed in AMI patients compared to healthy controls (Fig. 1f). To determine whether AMI activates $\alpha \beta$ T cells, we also examined the expression of CD69 of $\alpha \beta$ T cells in peripheral blood. Strikingly, there was, compared to controls, obvious increase in CD69 level of $\alpha \beta$ T cells, indicating that a significant activation of peripheral $\alpha \beta$ T cells occurred in AMI patients (Fig. 1g).

\section{Profiling of V, D and J gene segments usage after AMI}

Next, the usages patterns of V, D and J gene were measured by NGS approach based on multiplex PCR from peripheral $\alpha \beta \mathrm{T}$ cells. This yielded on $5.13 \times 10^{6}$ to $11.11 \times 10^{6}$ productively TCR $\beta$ blast reads per sample. The total number of TCR $\beta$ CDR3 reads was $0.57 \times 10^{4}$ to $7.60 \times 10^{4}$, with an average of $3.70 \times 10^{4} \mathrm{CDR} 3$ clonotypes per sample (Additional file 2: Table S1). In addition, a total of 56 distinct $\mathrm{V}$ gene segments and 14 distinct J gene segments from all samples (Additional file 3: Table S2). Overall, the usages of $\mathrm{V}$ and J gene segments were dominated by high-frequency segments in healthy controls, which top 10 TRBV accounted for $90.83 \%$ and top5 TRBJ accounted for $72.98 \%$. In contrast, top 10 TRBV only accounted for $62.77 \%$ and top5 TRBJ accounted for $58.83 \%$ in AMI patients (Fig. 2a, b). The most frequent $\mathrm{V}$ gene segments were TRBV20 (17.51\% in healthy controls, $12.77 \%$ in AMI patients). The most frequent J gene segments were TRBJ2-1 (18.43\% in healthy controls, $15.95 \%$ in AMI patients). Generally, the usage patterns and frequencies of most $\mathrm{V}$ and $\mathrm{J}$ genes were similar between healthy controls and AMI patients (Fig. 2c-e). However, these were significant differences in frequency of TRBV10-3, TRBV11-2, TRBV9, TRBV3-1, TRBV6-7 and TRBJ5-1 (Fig. 2f, g).

\section{Lower V-J and V-D-J combinations in AMI patients}

Furthermore, we also analyzed the composition of paired $\mathrm{V}-\mathrm{J}$ combinations and paired $\mathrm{V}-\mathrm{D}-\mathrm{J}$ combinations

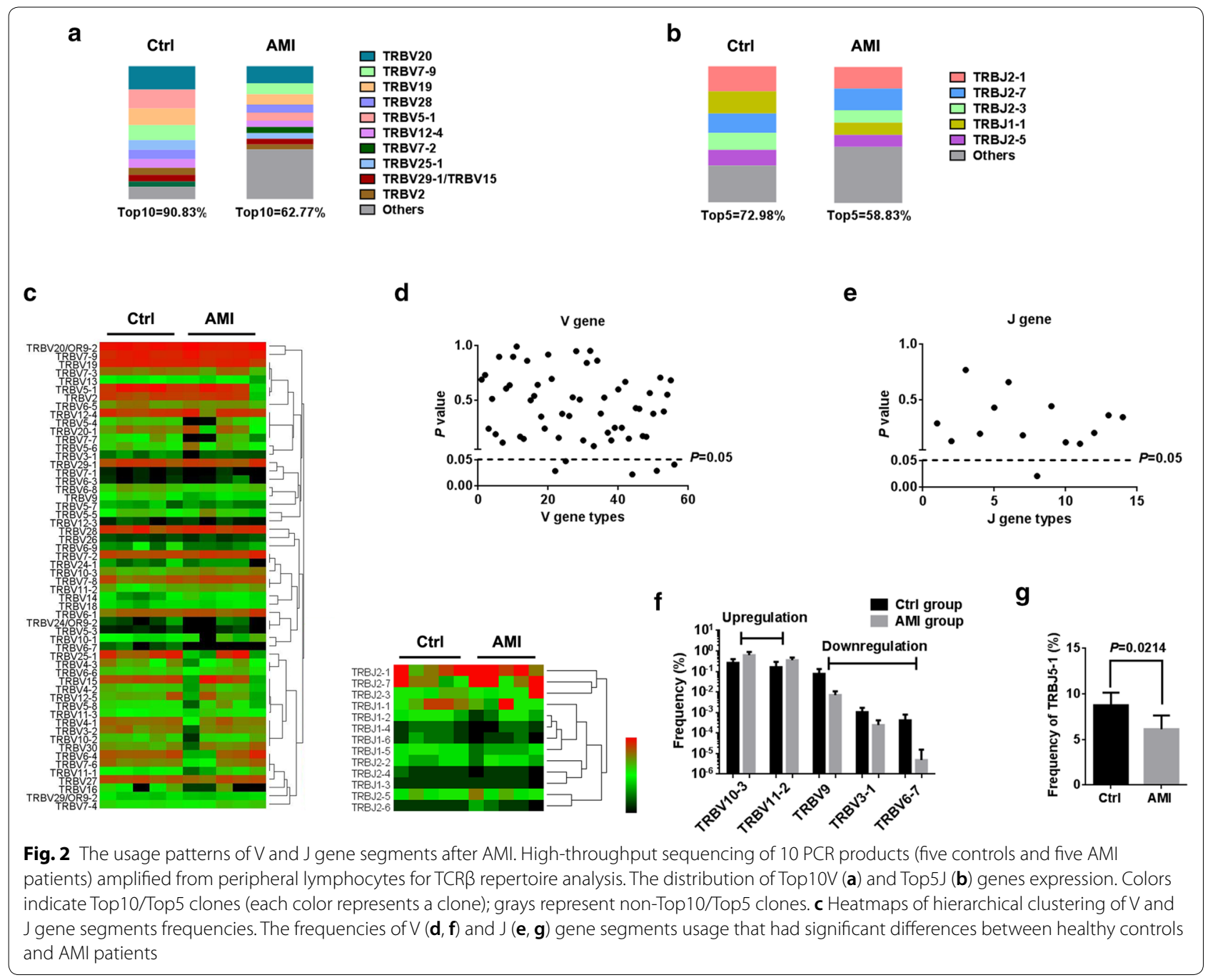


(Additional file 4: Table S3, Additional file 5: Table S4). Analysis of high-throughput sequencing of TCR $\beta$ chain repertoire led to the identification of 708 distinct $\mathrm{V}-\mathrm{J}$ combinations and 1304 distinct V-D-J combinations (Fig. 3a). Of note, AMI significantly resulted in reduced the clonotypes of $\mathrm{V}-\mathrm{J}$ and $\mathrm{V}-\mathrm{D}-\mathrm{J}$ combinations (Fig. 3b, c). The volcano plots were generated according to the usage frequency of $\mathrm{V}-\mathrm{J}$ combinations and $\mathrm{V}-\mathrm{D}-\mathrm{J}$ combinations. Compared to controls, there were $39 \mathrm{~V}-\mathrm{J}$ combinations and $51 \mathrm{~V}-\mathrm{D}-\mathrm{J}$ combinations that exhibited significantly abnormal usage in AMI patients. Interestingly, the frequencies of all altered V-J and V-D-J combinations were elevated in AMI patients, compared to healthy controls (Fig. 3d).

\section{AMI induces a diminished diversity of CDR3 AA}

Types of CDR3 AA clones determine the diversity of the TCR repertoires. In the current study, 360,274 distinct CDR3 AA clonotypes was identified (Additional file 6: Table S5). Although total TCR CDR3 AA clones were distinguishing among different individual, AMI, of note, led to obvious decreases in TCR $\beta$ base sequence clonotypes and CDR3 AA clonotypes (Additional file 1: Fig. S2a, b and Fig. 4a, b). Next, we quantified overlap of TCR $\beta$ base sequence and CDR3 AA clonotypes among different sample and found that overlap of TCR $\beta$ base sequence and CDR3 AA clonotypes in AMI patients were substantially higher than it in controls (Additional file 1: Fig. S2a, c and Fig. 4a, c). Gini coefficient, Simpson index and Shannon diversity suggested remarkably lessened CDR3 AA diversity in AMI patients (Fig. 4d-f). Rankabundance analysis also exhibited a shrunken CDR3 AA richness and evenness in AMI patients (Fig. $4 \mathrm{~g}$ ).

\section{Resetting of the CDR3 AA in AMI patients}

In order to investigate the reconstitution of CDR3 AA, Bhattacharyya distance was used to assess the similarity. As expected, Bhattacharyya distance clearly demonstrated a high similarity of CDR3 AA in AMI patients compared to healthy controls (Fig. 5a). In addition, we

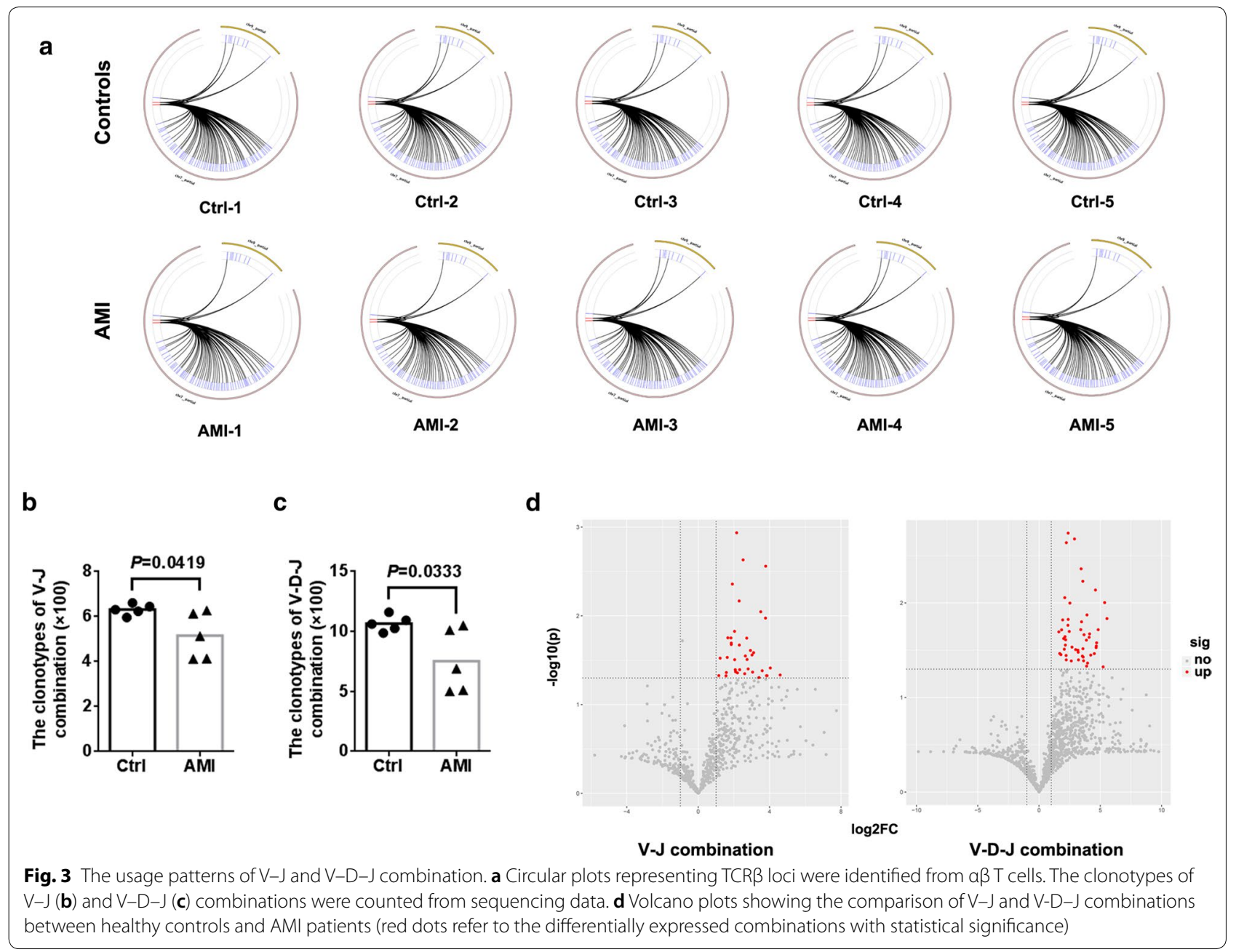




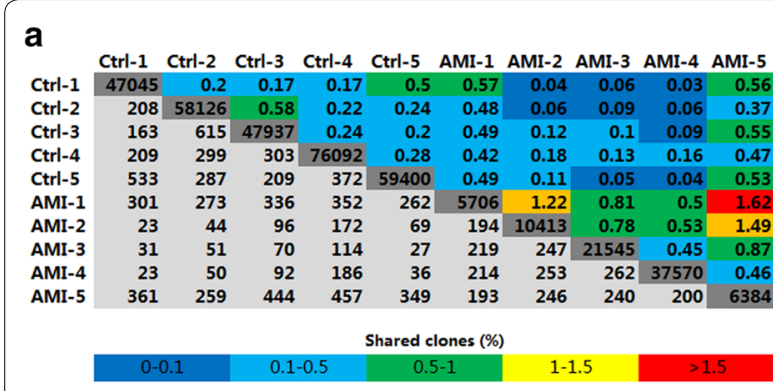

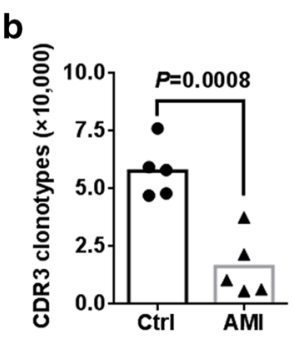

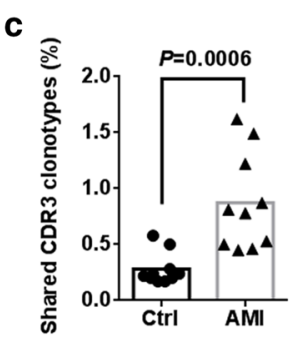

d

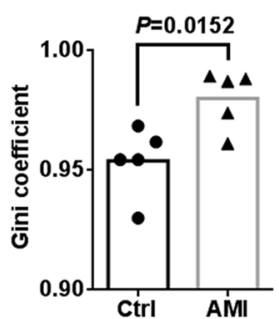

e

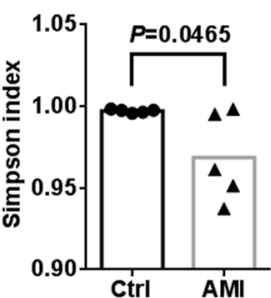

f

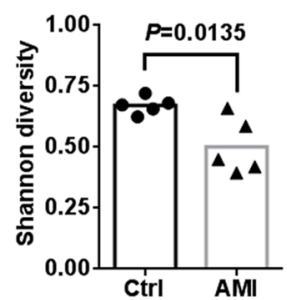

g

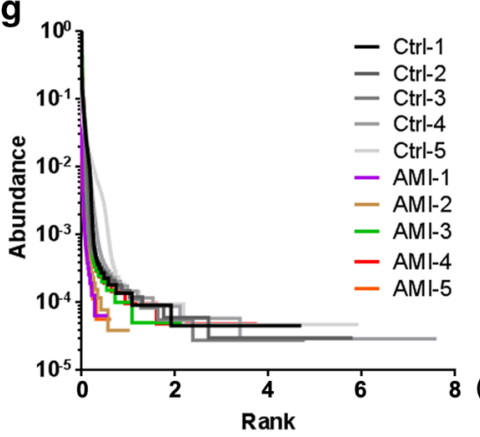

Fig. 4 The diversity of TCRß CDR3 AA clonotypes. a Quantification (plot grays) and frequencies (plot colors) of overlapping TCRß clonotypes. Light grays indicate the overlapping clonotypes, while dark grays indicate the total clonotypes per sample. Comparison of TCR $\beta$ repertoire diversity by total CDR3 AA clonotypes (b), shared CDR3 AA clonotypes (c), Gini coefficient (d), Simpson index (e) and Shannon index (f) between healthy controls and AMI patients. $\mathbf{g}$ Rank-Abundance analysis of CDR3 AA clonotypes among different samples
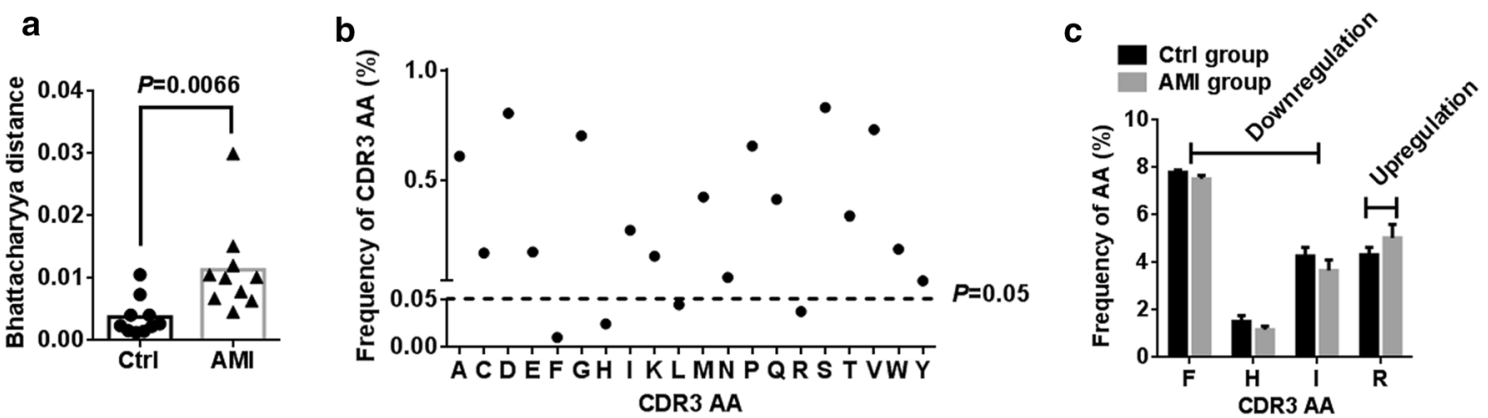

Fig. 5 Reconstitution of CDR3 AA after AMI. a Bhattacharyya distance analysis for the similarity of CDR3 AA from different group. $\mathbf{b}$ Comparison of the fraction of Top20 CDR3 AAs between healthy controls and AMI patients. c The frequencies of CDR3 AA that had significant differences were shown

evaluated the frequency of CDR3 AA usage in different samples (Additional file 7: Table S6). Of note, comparison of CDR3 AA usage showed that AMI induced aberrant CDR3 AAs usage of phenylalanine (downregulation), histidine (downregulation), leucine (downregulation) and arginine (upregulation) (Fig. 5b, c). However, there were no significant differences observed in length tendency in CDR3 AA length after AMI (Additional file 1: Fig. S3).

\section{Discussion}

Aberrant $\mathrm{T}$ cell function caused by AMI usually results in acute and chronic inflammatory processes that impair cardiac function [7, 22, 23]. Currently, despite a profound understanding of the adaptive immune system, and specifically the T cell response, in AMI, much less is known about TCR rearrangement. Accumulating evidence demonstrate that TCR repertoires will be rapidly reconstituted in response to endogenous and exogenous stimuli 
for immunosurveillance and immunoregulation [24-26]. Our preceding study indicates that TCR acts more like a "commander" than like an "executor" to monitor immune microenvironment [18]. Therefore, identifying and tracking TCR immune repertoires provide a novel method to understand the association between $\mathrm{T}$ lymphocytes and AMI injury.

The vast majority of data support that patients suffering AMI have significantly increased peripheral blood $\mathrm{T}$ cell activation though the decrease of $\mathrm{T}$ lymphocyte count occurred in the circulatory system $[10,11,27,28]$. Following AMI, $\mathrm{CD} 4^{+} \mathrm{T}$ cells can be activated, by presentation of myocardial peptides by dendritic cell [29]. It is considered that this activation process occurs within days and requires an intact $\mathrm{T}$-cell receptor repertoire. Recognition of cardiac autoantigens by TCR, presumably, is critical for maintaining the balance of control of AMI injury vs. T cell response, and facilitate wound healing of the myocardium [29]. Consistent with previous studies, our results revealed reduced percentage and enhanced activation of $\alpha \beta$ T cells in peripheral blood after AMI, demonstrating the crucial role of $\alpha \beta$ T cells in AMI $[11,30]$. Surely, enhanced activation of $\alpha \beta$ T cells can be attributed to AMI injury and heart failure. Nevertheless, the cause of diminishing $\alpha \beta \mathrm{T}$ cells in the process of AMI is still uncertain. It is speculated that several $\mathrm{T}$ cell subpopulations which exert immunosuppressive effect on myocardial inflammation vanish in this course, and TCR immune repertoires rearrangement occurs in order to recognize cardiac autoantigens, resulting $\mathrm{T}$ cells activation and myocardium injury. In this course, a massive activated $\mathrm{T}$ cells itself provides exact identification synergistically with other immunocytes to promote the pathogenesis.

Our work revealed an intact TCR $\beta$ profile of $\mathrm{V}, \mathrm{D}$ and $\mathrm{J}$ genes usage and the distribution of CDR3 AA clonotypes after AMI. In the current study, the frequencies of $\mathrm{V}$ and $J$ genes exhibited more centralized distribution though the majority of $\mathrm{V}$ and $\mathrm{J}$ genes were similar between healthy controls and AMI patients. It is noteworthy that the high clonal expansion frequencies of the TRBV103 , TRBV11-2 and the low clonal expansion frequencies of the TRBV9, TRBV3-1, TRBV6-7 and TRBJ5-1 were determined in AMI patients. It is suggested that such expand TRBV clones may be reactive $\mathrm{T}$ cell clones directed against AMI, while such lessened TRBV/TRBJ clones may act as immunosuppressive $\mathrm{T}$ cell clones in AMI. Moreover, AMI induced a diminished composition of $\mathrm{V}-\mathrm{J} / \mathrm{V}-\mathrm{D}-\mathrm{J}$ combination. Interestingly, the frequencies of all $\mathrm{V}-\mathrm{J} / \mathrm{V}-\mathrm{D}-\mathrm{J}$ combinations that had significant differences after AMI were upregulated unanimously, partly as a result of reduced composition of $\mathrm{V}-\mathrm{J} / \mathrm{V}-$ D-J combination and partly because AMI restrains immunosuppressive $\mathrm{T}$ cell subsets emergence. These data were consistent with the results in Fig. 1, which indicate that a lower percentage of peripheral $\alpha \beta$ T cells was observed in AMI patients.

CDR3, composed of variable $(\mathrm{V})$, diversity (D), and joining $(\mathrm{J})$ domains from the terminal of the $\mathrm{V}$ domain to the beginning of the J domain, is considered as a critical region to recognize antigen. The specificity and diversity of TCR repertoires is dependent of CDR3 AA clonotypes [31, 32]. In this work, obviously decreased CDR3 clonotypes and altered CDR3 AAs were observed in AMI patients, suggesting that AMI led to a shrunken TCR $\beta$ diversity and VDJ recomposition. Among AMI patients, the proportion of shared CDR3 AA was obviously elevated compared to that among healthy controls, which imply that AMI induced the usage of several key high-frequency CDR3 AAs. Our observation of transformation of TCR $\beta$ repertoire after AMI provides evidence of AMI-associated immune repertoire in AMI injury progression. These results indicate that transformation of TCR immune repertoires is indispensable for antigen recognition in the adaptive immune system for myocardial injury.

Undoubtedly, AMI-responsive TCR $\beta$ immune repertoire represents a "footprint" of immune microenvironment in peripheral blood, which will be conducive to better understanding of the function of $\alpha \beta \mathrm{T}$ cell in myocardial injury after AMI. However, the mechanism and effect of TCR $\beta$ reconstitution in T cell activation are still not clear, and how TCR $\beta$ immune repertoire modulates the inflammatory milieu needs to be further investigated. Of note, a recent study finds the difference in expression pattern and clonality of TCR $\gamma \delta \mathrm{T}$ cells between AMI patients and healthy individuals, reflected by the obviously restricted TCR $\gamma \delta$ subfamilies expression in $\gamma \delta \mathrm{T}$ cells from AMI patients [33]. The preceding data along with our result indicate an important role of $\alpha \beta$ and $\gamma \delta$ T cells in AMI injury, and reconstitution of TCR immune repertoires participate in modulation of inflammatory status.

\section{Conclusions}

Our work first reveals the characteristic of the TCR $\beta$ immune repertoire after AMI. Through its tracking of the kinetics of the reconstitution of TCR $\beta$, we find significantly restricted TCR $\beta$ immune repertoire and the discrepancy in the expression of $\alpha \beta$ T subsets, which may be related to the immune response and clinical outcome. These data provide a novel insight to identify signatures of AMI-associated immune microcircumstance, which will accelerate discoveries of novel immunotherapy for AMI patients. 


\section{Additional files}

Additional file 1: Fig. S1. Two-round nested amplicon arm-PCR for TCR $\beta$ immune repertoire. $n=5$ per group. Fig. S2. The clonotypes analysis of TCR $\beta$ base sequence. a Quantification (plot grays) and frequencies (plot colors) of base sequence clonotypes. Light grays indicate the overlapping clonotypes, while dark grays indicate the total clonotypes per sample. b Comparison of total clonotypes of TCR $\beta$ base sequence. $\mathbf{c}$ The percentage of overlapping base sequence between healthy controls and AMI patients. Fig. S3. The distribution of CDR3 AA length between healthy controls and AMl patients. $n=5$ per group.

Additional file 2: Table S1. The analysis of TCR $\beta$ immune repertoire sequencing data.

Additional file 3: Table S2. The distribution of $V$ and $J$ gene segments in each sample.

Additional file 4: Table S3. The distribution of $\mathrm{V}$-J combinations in each sample.

Additional file 5: Table S4. The distribution of V-D-J combinations in each sample.

Additional file 6: Table S5. The distribution of CDR3 AA clonotypes in each sample.

Additional file 7: Table S6. The distribution of AA usage in CDR3.

\section{Abbreviations}

AMl: acute myocardial infarction; TCR: T cell receptor; CDR3: complementary determined regions 3; AA: amino acids; MHC: major histocompatibility complex; APCs: antigen-presenting cells; NSG: next-generation sequencing; cTnl: cardiac troponin-I; PCl: primary percutaneous intervention; TRBV: TCR $\beta$ V gene; TRBJ: TCRß J gene; IMGT: ImMunoGeneTics.

\section{Authors' contributions}

KW contributed to the study conception and design; DL, QL, CZ and YS performed the experiments; LH, QL and BW analyzed the data; KW contributed to manuscript drafting and supervision. All authors read and approved the final manuscript.

\section{Author details}

${ }^{1}$ Department of Cardiology, The Affiliated Hospital of Qingdao University, Qingdao, Shandong, China. ${ }^{2}$ College of Basic Medicine, Qingdao University, Qingdao, Shandong, China. ${ }^{3}$ Department of Cardiovascular Medicine, The Affiliated Cardiovascular Hospital of Qingdao University, Qingdao, China.

${ }^{4}$ Center of Patients, West China Second University Hospital, Sichuan University, Chengdu, China.

\section{Acknowledgements}

Not applicable.

\section{Competing interests}

The authors declare that they have no competing interests.

\section{Availability of data and materials}

The datasets supporting the conclusions of this article are included within the article.

\section{Consent for publication}

Not applicable.

\section{Ethics approval and consent to participate}

Human subjects: This study was approved by the Ethics Committee of The Affiliated Hospital of Qingdao University and written informed consent was obtained from each participant.

Animals: Not applicable.

\section{Funding}

This work was supported by the Natural Science Foundation of Shandong Province Project (ZR2016HP17) and the Postdoctoral Application Research of Qingdao Project (2016063).

\section{Publisher's Note}

Springer Nature remains neutral with regard to jurisdictional claims in published maps and institutional affiliations.

Received: 17 September 2018 Accepted: 4 February 2019

Published online: 06 February 2019

\section{References}

1. Hansson GK, Libby P. The immune response in atherosclerosis: a doubleedged sword. Nat Rev Immunol. 2006;6:508-19.

2. Go AS, Mozaffarian D, Roger VL, Benjamin EJ, Berry JD, Blaha MJ, Dai S, Ford ES, Fox CS, Franco S, et al. Heart disease and stroke statistics-2014 update: a report from the American Heart Association. Circulation. 2014;129:e28-292.

3. Shepard D, VanderZanden A, Moran A, Naghavi M, Murray C, Roth G. Ischemic heart disease worldwide, 1990 to 2013: estimates from the global burden of disease study 2013. Circ Cardiovasc Qual Outcomes. 2015;8:455-6.

4. Jia L, Zhu L, Wang JZ, Wang XJ, Chen JZ, Song L, Wu YJ, Sun K, Yuan ZY, Hui R. Methylation of FOXP3 in regulatory T cells is related to the severity of coronary artery disease. Atherosclerosis. 2013;228:346-52.

5. Lu Y, Li L, Yan H, Su Q, Huang J, Fu C. Endothelial microparticles exert differential effects on functions of Th1 in patients with acute coronary syndrome. Int J Cardiol. 2013;168:5396-404.

6. Zhang Y, Lin P, Jiang H, Xu J, Luo S, Mo J, Li Y, Chen X. Extensive serum biomarker analysis in patients with ST segment elevation myocardial infarction (STEMI). Cytokine. 2015;76:356-62.

7. Hofmann U, Frantz S. Role of T-cells in myocardial infarction. Eur Heart J. 2016;37:873-9.

8. Stephenson E, Savvatis K, Mohiddin SA, Marelli-Berg FM. T-cell immunity in myocardial inflammation: pathogenic role and therapeutic manipulation. Br J Pharmacol. 2017;174:3914-25.

9. Raffaghello L, Bianchi G, Pistoia V. Immunosuppressive treatments in acute myocardial infarction and stroke. Curr Pharm Biotechnol. 2012;13:59-67.

10. Turner NA. Inflammatory and fibrotic responses of cardiac fibroblasts to myocardial damage associated molecular patterns (DAMPs). J Mol Cell Cardiol. 2016;94:189-200.

11. Napoleao P, Selas M, Freixo C, Carmo MM, Viegas-Crespo AM, Ferreira RC, Pinheiro T. T lymphocytes alterations are associated with oxidized LDL, troponin T, white blood cells and C-reactive protein during acute myocardial infarction. Clin Hemorheol Microcirc. 2013;55:349-58.

12. Roche PA, Cresswell P. Antigen processing and presentation mechanisms in myeloid cells. Microbiol Spectr. 2016. https://doi.org/10.1128/micro biolspec.MCHD-0008-2015.

13. Chen L, Flies DB. Molecular mechanisms of T cell co-stimulation and coinhibition. Nat Rev Immunol. 2013;13:227-42.

14. Singhal A, Mori L, De Libero G. T cell recognition of non-peptidic antigens in infectious diseases. Indian J Med Res. 2013;138:620-31.

15. Poschke I, Flossdorf M, Offringa R. Next-generation TCR sequencinga tool to understand T-cell infiltration in human cancers. J Pathol. 2016:240:384-6.

16. Hou D, Ying T, Wang L, Chen C, Lu S, Wang Q, Seeley E, Xu J, Xi X, Li T, et al. Immune repertoire diversity correlated with mortality in avian influenza $A$ (H7N9) virus Infected patients. Sci Rep. 2016:6:33843.

17. Thygesen K, Alpert JS, Jaffe AS, Simoons ML, Chaitman BR, White HD, Joint ESCAAHAWHFTFftUDoMI, Katus HA, Lindahl B, Morrow DA, et al. Third universal definition of myocardial infarction. Circulation. 2012;126:2020-35.

18. Liang Q, Liu Z, Zhu C, Wang B, Liu X, Yang Y, Lv X, Mu H, Wang K. Intrahepatic $T$ cell receptor beta immune repertoire is essential for liver regeneration. Hepatology. 2018. https://doi.org/10.1002/hep.30067. 
19. Chen Y, Xu Y, Zhao M, Liu Y, Gong M, Xie C, Wu H, Wang Z. High-throughput $T$ cell receptor sequencing reveals distinct repertoires between tumor and adjacent non-tumor tissues in HBV-associated HCC. Oncoimmunology. 2016;5:e1219010.

20. Birtel J, Walser JC, Pichon S, Burgmann H, Matthews B. Estimating bacterial diversity for ecological studies: methods, metrics, and assumptions. PLOS ONE. 2015:10:e0125356.

21. Sims JS, Grinshpun B, Feng Y, Ung TH, Neira JA, Samanamud JL, Canoll P, Shen Y, Sims PA, Bruce JN. Diversity and divergence of the glioma-infiltrating T-cell receptor repertoire. Proc Natl Acad Sci USA. 2016;113:E3529-37.

22. Kaplan A, Altara R, Eid A, Booz GW, Zouein FA. Update on the protective role of regulatory $T$ cells in myocardial infarction: a promising therapy to repair the heart. J Cardiovasc Pharmacol. 2016;68:401-13.

23. Novak J, Dobrovolny J, Tousek P, Kocka V, Teringova E, Novakova L, Widimsky P. Potential role of invariant natural killer T cells in outcomes of acute myocardial infarction. Int J Cardiol. 2015;187:663-5.

24. Maryanski JL, Casanova JL, Falk K, Gournier H, Jaulin C, Kourilsky P, Lemonnier FA, Luthy R, Rammensee HG, Rotzschke O, et al. The diversity of antigen-specific TCR repertoires reflects the relative complexity of epitopes recognized. Hum Immunol. 1997:54:117-28.

25. Attaf M, Huseby E, Sewell AK. alphabeta T cell receptors as predictors of health and disease. Cell Mol Immunol. 2015;12:391-9.

26. Boudinot P, Marriotti-Ferrandiz ME, Pasquier LD, Benmansour A, Cazenave PA, Six A. New perspectives for large-scale repertoire analysis of immune receptors. Mol Immunol. 2008;45:2437-45.
27. Zhai S, Zhang L, Dang S, Yu Y, Zhao Z, Zhao W, Liu L. The ratio of Th-17 to Treg cells is associated with survival of patients with acute-on-chronic hepatitis B liver failure. Viral Immunol. 2011;24:303-10.

28. Methe H, Brunner S, Wiegand D, Nabauer M, Koglin J, Edelman ER. Enhanced T-helper-1 lymphocyte activation patterns in acute coronary syndromes. J Am Coll Cardiol. 2005;45:1939-45.

29. Hofmann U, Beyersdorf N, Weirather J, Podolskaya A, Bauersachs J, Ertl G, Kerkau T, Frantz S. Activation of CD4+ T lymphocytes improves wound healing and survival after experimental myocardial infarction in mice. Circulation. 2012;125:1652-63.

30. Hosono M, de Boer OJ, van der Wal AC, van der Loos CM, Teeling P, Piek $\mathrm{JJ}$, Ueda M, Becker AE. Increased expression of T cell activation markers (CD25, CD26, CD40L and CD69) in atherectomy specimens of patients with unstable angina and acute myocardial infarction. Atherosclerosis. 2003; 168:73-80.

31. Armstrong KM, Piepenbrink KH, Baker BM. Conformational changes and flexibility in T-cell receptor recognition of peptide-MHC complexes. Biochem J. 2008:415:183-96.

32. Fozza C, Barraqueddu F, Corda G, Contini S, Virdis P, Dore F, Bonfigli S, Longinotti M. Study of the T-cell receptor repertoire by CDR3 spectratyping. J Immunol Methods. 2017;440:1-11.

33. Chen XM, Zhang T, Qiu D, Feng JY, Jin ZY, Luo Q, Wang XY, Wu XL. Gene expression pattern of TCR repertoire and alteration expression of IL-17A gene of gammadelta T cells in patients with acute myocardial infarction. $J$ Transl Med. 2018;16:189.
Ready to submit your research? Choose BMC and benefit from:

- fast, convenient online submission

- thorough peer review by experienced researchers in your field

- rapid publication on acceptance

- support for research data, including large and complex data types

- gold Open Access which fosters wider collaboration and increased citations

- maximum visibility for your research: over 100M website views per year

At BMC, research is always in progress.

Learn more biomedcentral.com/submissions 